\title{
LABOUR MARKET RESEARCH IN NEW ZEALAND
}

\author{
Philip S. Morrison \\ Victoria University of Wellington
}

\section{Opening Address}

Welcome to the Fifth Conference on Labour, Employment and Work (LEW). The registration of over 100 participants at this conference from a wide range of government departments, private sector research units and universities is indicative of our collective concem for labour and employment issues in this country. It is also indicative of the high turnover of departmental staff on desks directly or indirectly concerned with employment issues. Every year we see the transfer of responsibility for employment issues to new staff many of whom are expected to quickly bring themselves up-to-date on the state of the New Zealand labour market, the main directions of research and the availability of researchers. This turnover reinforces the continuing need for a forum such as this in which knowledge from recent research can be shared and discussed. These meetings allow those new to the field to be integrated into the informal networds that have developed over the years.

Despite unemployment being top of the list of public concerns since the early 1980 s there has not been any clear leadership from any central body on the direction and focus for research in this area. Instead we have a variety of public and private research organisations and individual contractors who address aspects of the problem for short durations. Little has changed in this respect since the early 1980 s when the first of these conferences was held. We still try and debate labour and employment policy in New Zealand in a largely uncoordinated, under funded and under researched environment in which debates over ideology too often substitute for sound research.

One of the consequences of an uncoordinated research environment is lack of communication on research priority setting. Two developments may alter, if not radically change, this situation in the years to come: the introduction of the Public Good Science Fund (PGSF) and the establishment of the Labour Statistics Unit within the Department of Statistics .

As a result of the centralisation of State research funding in New Zealand under the PGSF most of us here will be forced to coordinate our research both within and across Universities and Crown Research Institutes and among private research consultants. The emphasis will be on programmes of research under which coordinated research projects will be designed. The orientation and direction of that research itself will be highly influenced by the governments own set of priorities. Through control over funding the PGSF will now exercise unprecedented central control over the degree of cooperation, direction and quality of research into labour and employment issues in New Zealand.

The PGSF is both an exciting opportunity to address many of the pitfalls present in the existing uncoordinated environment but it is also one that is thwart with potential difficulties. While PGSF will encourage joint work it may also have the effect of encouraging 'teams' of researchers keeping their ideas and research work under wraps in what has already become a very competitive funding environment. If this were to occur it would be an unfortunate development which would exacerbate the intellectual isolationism which conferences like these are designed to redress.

The second development with potential for changing the direction of labour and employment research is the development of the Labour Statistics Unit within the Department of Statistics. Discussion of the background to this unit and the proposal to redesign the collection of statistics relevant for labour market analysis is contained in part 11 of these proceedings. Certainly the Labour Statistics Unit has a potentially valuable role to play in providing data on those areas of research which are receiving inadequate attention or are inhibited because data is not bring provided in the appropriate form. In the absence of strong research leadership from elsewhere suppliers of data end up playing a major role in setting research agendas. Whether we like it or not research is often undertaken because the data is available rather than because the question is of foremost practical, policy or theoretical importance.

What ever their merits, neither the PGSF nor the new Labour Statistics Unit actually come up with the research questions themselves; nor do they provide the conceptual and research skills necessary to address them. For both these one must look to the combined role of the Universities, private research institutions and the large government departments with specific interests in understanding the operation of the labour market, its institutional setting and their economic and social consequences. The Universities must be seen to be providing the basic conceptual and technical training and the research centres and government 
departments must continue to offer the necessary on-thejob research training.

Driving the research effort are the research questions themselves. Some arise 'naturally' out of policy problems and the information required to mount effective programmes. The majority of research however comes from the perceptions of researchers - on the basis of existing New Zealand and international literature and/or an understanding of what is actually happening on the ground. It is instructive therefore to look at the new crop of research questions being investigated by researchers at this conference. In order to focus our collective the attention I have asked each author to end their papers with an explicit section entitled Future Research. The results are instructive.

\section{Overview and future research}

One of the striking features of the twenty research papers included here is their breadth. This is reflected in the fact that a total of ten sections were required to categorise them. What follows is a brief summary of what I have taken as the most salient points of those papers and their implications for future research.

For the first time in the post-war New Zealand we are seeing the labour force contract while the working age population continued to expand. Krishnan, Hunter and Goodger demonstrate this gap and how the labour force participation rates of both men and women have been falling since the mid 1980s. These are trends which have been especially pronounced for the Maori and Pacific Island Polynesian. The latter with 3 percent of population now make up 10 percent of the unemployed. And among the unemployed the long term unemployed are making up an increasing proportion. Their market reentry and dynamics associated with periods of unemployment are still poorly understood. This is therefore an ongoing research need as is the longitudinal data necessary to better understand the paid and unpaid employment history of those involved.

Research which focusses on dynamics is particularly welcome but the availability of data is crucial. In one of the first steps to exploit the panel properties of the Household Labour Force Survey Grimmond explores the quantitative relationship between the various states of unemployment, employment and being outside the market. Increasingly periods of unemployment reduce the propensity to secure paid work. But subpopulations differ substantially and Grimmond's research shows that men and women in particular differ in their likelihood of moving from employment into unemployment and in opting to leave the market for paid labour itself.

In a research effort which also focuses on market entry Poot and Seigers explore the relationship between labour market conditions such as wages and levels of unemployment and the decisions by women to (re)enter the labour force and/or have additional children. The results for New Zealand appear to support the expectations of those models which are based on economic interpretations of child bearing decision making and the rational calculation of the relative benefits of having children. These results are based on highly aggregate data however and now need to be complemented by analysis which shows how particular demographic and socioeconomic sub-groups behave. Such information may well determine the marginal influence of social policies on family costs and hence on who looks for work, when and where.

A welcome feature of this fifth Labour, Employment and Work (LEW) conference was the attention drawn to the global nature of the conditions which contributes to high and sustained unemployment. What is required argues Le Heron is an appreciation of the wider international framework within which the domestic considerations dominating, employment research can the placed. This is a conceptual paper only however and translating the broad metaphors of globalisation and internationalisation into clear research questions is an obvious challenge to subsequent research.

An understanding of the role of tariffs is one specific example of the interface between international conditions and domestic employment. Willis compares the New Zealand and Australian experience and points out how little we actually know about the direct and indirect employment effects of changes in levels of protection. Job losses in Australia have been spread over the last 20 years and this partly explains why the much shorter period of job losses in the New Zealand manufacturing sector has been relatively more severe than in Australia despite this country's higher rate of protection.

The international theme is picked up again by geographers Friesen, Bedford and Lidgard. Friesen explores the economic and social impact of legislation encouraging Asian migration. Levels of migration from Asia have recently surpassed levels from traditional source areas in Europe and Pacific Islands. Their settlement in New Zealand is geographically concentrated with with more than half settling in Auckland. Spatial concentration of Asian settlement within Auckland is also observable. Friesen points out the need need for research into the net impact of this policy decision both on the migrants themselves and the host society.

Bedford and Lidgard also draw our attention to the possible consequences of an immigration policy which by admitting those with broad skills base might be failing to recognise the employment needs of those New Zealanders who are returning migrants. The experience of returning migrants is carefully examined. Why, ask these authors, when returning migrants express such difficulty in obtaining employment is the Government persisting with a broad base point system and not trying to match immigrants with those specific jobs which cannot be filled domestically? 
Sitting as a backdrop to studies of individuals and groups within the labour market are those broad sectoral trends which influence both the product of labour itself and the skills employers require. It is the recent change in the ability of sectors to provide employment and the influence they are having on the demand for labour from particular socio-economic groups which are explored by Callister. The shift away from those manual jobs requiring informal skills to service sector positions requiring formal qualifications has had particularly serious consequences for Maori employment. This in turn raises questions about the nature of skills required for successful competition within the growing service sector and how access to these skills can be widened.

In our emphasis on the workplace it is easy to forget the tens of thousands of New Zealanders who work at home. Home work, argues Loveridge, appears to be associated with minority groups with limited access to the labour market. Working at home is therefore associated with vulnerability and a predominantly female work force. At the same time those who work at home are a very heterogeneous group and, while there are likely to be considerable benefits from the technological developments such as home computing, how these benefits are shared and whether they begin to address the more vulnerable of home workers constitutes an on-going research question.

Notwithstanding the international context, the sectoral background, the complex dynamics and the intrinsic connections between family, households and workplace decisions, the majority of research reported at this conference had to do with what was going on in the workplace itself. A number took a single industry and explored the apparent consequences of the pressure for increased flexibility on labour.

The export meat industry case proved to be fertile ground for such an investigation. In his paper Curtis explores the impact of movement from mass to niche markets on union control and industrial relations in the workplace. Reveley asks similar questions of the waterfront industry in particular how the unique characteristics of waterfront industry led to the emergence of a type of unionism that focussed primarily on controlling the supply of labour within local labour markets. Deregulation eroded the control of this 'bureau system' and now raises important research questions about the way in which individual firms are handling industrial relations in a post-deregulated environment.

The nature of contemporary change in New Zealand's traditional industries is also well illustrated by Gibson's ongoing research into the dairy manufacturing industry. This industry faced a choice between continuing to produce low priced products using low wages and low skills and restructuring to produce high price quality markets using a reduced but with a highly skilled workforce. The consequences of the latter choice on the workplace have been worth monitoring. As their skills broadened so did workers responsibilities with this came the need to understand more of the manufacturing process itself and ultimately more about management. The result of decisions to produce for different markets is an ongoing transformation of the workplace industrial relations reform. Monitoring and documenting the metamorphosis in this industry will continue to be an important contribution to labour research.

A further step is to actually put in place action research methods to explore alternative management structures and the decision making process. Capper and Hill report on such a project aimed at documenting successful practice in New Zealand secondary schools. Initiated by the Teacher's Union this project is driven as much by the considerable pressure being placed on school staff by recent educational and industrial reforms as it is by any academic questions. This is an interesting example of action research whose results are worth following closely.

In periods of rapid legislative change monitoring occupies a particularly important place in the range of research activities. The survey of workplaces undertaken by Anderson, Brosnan and Walsh for example sought to identify the kinds of changes undertaken by a wide range of employers following deregulation. Unsurprisingly the conclusions are unclear. Short term reactions to immediate recession clouds any clear identification of strategy and easily measured changes such as workforce reduction overshadow more subtle adjustment strategies. Their waming on inferring 'casualisation' as a response therefore is well taken. Such postal surveys can only be a crude first step in understanding labour adjustment. Their research highlights the need for research programmes which, by being more tightly focussed on particular industries, can more clearly establish the complex lines of cause and effect in labour adjustment patterns.

Underlying greater attention to response within individual workplaces is a concern over the operation or and immediate impacts of the Labour Contracts Act. Focussing on changes in working time arrangements Harbridge and Tolich also highlight the variety in response and consequent difficulties in generalising over a range of industries. The length of the work week, scheduling and the overtime and penal rates have all be subject to alteration but rarely across the board. As in the previous paper the need for closer research attention to specific industries and firms is highlighted in this paper.

Similar difficulties in generalisation apply when broad employee groups are surveyed. In an innovative paper Hanna and Peterson explore the knowledge which young people have of their own contract and the Labour Contracts Act. As might be expected knowledge is quite incomplete, of the type of contract they had, how it was negotiated and what it actually said. Unfortunately when there is little choice of employment, little is to be gained by employees from careful scrutiny of their contracts. At present however this lack of knowledge can only contribute to their 
vulnerability. Again, systematic rather than ad hoc monitoring of the transition from compulsory education to paid work would yield valuable results.

Pay equity suffers similar problems. As Hyman points out in her review, the success of pay equity initiatives are more dependent on favourable economic, political and industrial relations climates than the details of initiatives. These same factors are likely to widen rather than narrow the pay gap between men and women. This hardly reduces the importance however of monitoring and refining the research tools necessary to measure pay equity internationally, among specific subgroups and within large enterprises.

For those without jobs however the issues have more to do with securing employment than debating the conditions. Getting people back to work was a major aim of schemes like ACCESS and those that now succeed it. Just how successful this scheme was relative to the Job Opportunities and Job Seeker schemes was assessed in a very detailed analysis by Dominick. ACCESS was more successful in improving job prospects but characteristics of individuals as opposed to the schemes continued to play the dominant role in determining outcomes: their attendance at workbased or vocational training, their job search behaviour, experience, levels of education and ethnicity were all important factors. At the same time there are scheme related results which are important such as those that show that life skills rather than vocational training is more closely associated with increased employment outcomes. Such research is clearly important but only as long as it continues to be fed into subsequent programme design.

Training for successful employment is predicated on the assumption that jobs are or will become available. In many cases this is still a long term goal rather than a present reality. Not suprisingly therefore promotion of self employment has become a complementary part of employment policy. Whether the current approach to local initiatives are appropriate is the question being asked by Perry on the basis of the Scottish experience. That experience demonstrates the capacity of community enterprise to generate jobs but not on the scale needed to replace main stream job loss. It is relevant to note therefore Perry's suggestion that alternatives to the present enterprises may be more likely to generate jobs. Community cooperatives and credit unions seem better able to mobilise local communities. Such ideas are worthy of a systematic research effort.

A survey of the 20 research papers in this volume shows that labour and employment research in New Zealand continues to advance on four main fronts: the analysis of flows and dynamics within the labour market, the analysis of net job change by sector and industry, the monitoring of the ongoing transformation of work and workplace practices and fourthly, the assessment of government employment initiatives.
Of equal importance however is the way the conference has exposed areas where work is lacking. One area that does need closer attention is in understanding the domestic employment consequences of international developments. Such research can range from examining specific changes such as tariff reductions through to the short and long term implications of the increasing number of 'local' jobs dependent on decisions being made by transnational corporations.

Despite the amount of research on the topic in New Zealand there are still quite inconclusive results on the nature of labour adjustments within firms - many of which are reacting to changes in overseas markets and domestic consequences of foreign imports. We need to advance past the 'shopping list' approach to documenting adjustments which come from survey work to more sophisticated research designs which can lead to the identification of clear models of labour adjustments in particular settings. Here the research from the industry case studies reported here are instructive for they suggest a much greater chance of understanding adjustments within particular well defined institutional and geographic contexts. In this respect the number of new scholars presenting material from ongoing or recently completed thesis work tied to understanding responses in the workplaces of particular industries in their historical and institutional setting is highly relevant and encouraging. 